\title{
Rethinking health planning: a framework for organising information to underpin collaborative health planning
}

Ori Gudes, Elizabeth Kendall,Tan Yigitcanlar,Virendra Pathak and Scott Baum

\begin{abstract}
The field of collaborative health planning faces significant challenges created by the narrow focus of the available information, the absence of a framework to organise that information and the lack of systems to make information accessible and guide decision-making. These challenges have been magnified by the rise of the 'healthy communities movement', resulting in more frequent calls for localised, collaborative and evidence-driven health related decision-making.This paper discusses the role of decision support systems as a mechanism to facilitate collaborative health decision-making.The paper presents a potential information management framework to underpin a health decision support system and describes the participatory process that is currently being used to create an online tool for health planners using geographic information systems. The need for a comprehensive information management framework to guide the process of planning for healthy communities has been emphasised.The paper also underlines the critical importance of the proposed framework not only in forcing planners to engage with the entire range of health determinants, but also in providing sufficient flexibility to allow exploration of the local setting-based determinants of health.
\end{abstract}

\section{Keywords (MeSH):}

Clinical Decision Support Systems; Health Planning; Community Health Planning; Primary Healthcare; Healthy People Programs; Collaboration; Information Management; Evidence-Based Healthcare.

\section{Introduction}

In the last few decades there has been an increase in the application of broader approaches to disease management that focus on the creation of healthy communities. The healthy communities model has become a focus of international and local efforts to combat chronic disease and improve the overall health of citizens. The success of these initiatives depends heavily on the capacity of the community to plan effectively for its future health and address the complex array of factors that influence health outcomes.

Such complex endeavours are likely to require new methods of planning that engage multiple stakeholders in decision-making and draw on diverse bodies of information to explore complex determinants of health. For this reason, Northridge, Sclar and Biswas (2003) emphasised that stronger collaborations were needed between urban planners, health policy-makers, public health practitioners and community members to ensure effective design and planning for healthy communities. In response to calls of this nature, a model of planning known as collaborative health planning has evolved to become one of the key foundations of modern health planning. Collaborative health planning is grounded in both 'communicative planning theory' and 'population health theory'. For instance, Murray (2006) emphasised that collaborative planning practice will become fundamental to planning in the near future. Furthermore, Healey (1993) stated that 
communicative planning theory represents the most appropriate paradigm to underpin, inform and shape collaborative planning practice. In the context of population health theory, Barnard and Hu (2005) noted that this approach strives to ensure that the health system is appropriately oriented to improve the health status of the population by applying evidence-based practice across the continuum from health determinants to service interventions. According to Plescia Joyner and Scheid (2004), large health care systems seeking to create collaborative health planning projects that impact at the community level, face many challenges. Some of these challenges include building local capacity, supporting comprehensive approaches to health and prevention, increasing diverse participation in public health planning, supporting local structure and identifying additional funding sources for maintaining sustainability.

Irrespective of their approach in working towards solutions for health issues, one of the major challenges faced by health planners is access to meaningful information that provides them with the breadth of knowledge required to make effective decisions about the local area. In this regard, a recent review of the health system in Queensland, Australia, concluded that despite the availability of a wealth of data about health, little of this information actually assisted districts in their service planning and performance evaluation (Queensland Health 2005). In a more recent report, it was noted that 'a barrier to identifying needs for community-based services is the limited data available and lack of prediction methodologies' (Auditor-General of Queensland 2009: 2). Even when sufficient information is available, the skills needed to interpret and translate information into effective decisions vary considerably. This lack of access to data may be associated with the absence of a central health data repository and the multiplicity of data sources, formats and systems that exist across different health organisations. In a recent Australian health review, it was noted that the smart use of system data, internal information and publicly available information on health is essential to generate informed decision-making (National Health and Hospitals Reform Commission 2009). The report suggested increasing and improving innovation and research that may lead to an improved knowledge-based capability.

These aforementioned reasons indicate that there is an urgent need to develop a framework for organising information, selecting a suitable method for accessing this, and choosing an appropriate approach for health planning activities that can translate these complex datasets into meaningful decisions, which eventually address the big challenge of building healthy communities.

Research has justified the use of decision support systems (DSS) in planning for healthy communities as these systems have been found to improve the planning process (Cromley \& McLafferty 2003). DSS are information communication technology (ICT) tools including geographic information systems (GIS) that provide the mechanisms to help decision-makers and related stakeholders assess complex problems and solve these in a meaningful way (Shim et al. 2002; Yigitcanlar \& Gudes 2008). However, knowledge about the nature and use of DSS within collaborative health planning is relatively limited. Nevertheless, these systems have been gaining prominence in recent years, having been described by several researchers over the last few decades (Reinke 1972; Reeves \& Coile 1989; Higgs \& Gould 2001) as an efficient support tool for health planning. Reeves and Coile (1989) stated that DSS increases the ease of access to data and provides greater usability. Higgs and Gould (2001) suggested that a range of DSS features could contribute to effective health planning, including the ability to construct 'what if' scenarios (e.g. to assess the impact of new services and infrastructure), identify 'underserved' areas (e.g. where need or growth outstrips facilities), evaluate the quality and accessibility of health services or health care information (e.g. usage and uptake), locate particular healthcare facilities or community assets (e.g. changes in service systems over time), conduct reliable health surveillance (e.g. patterns of disease), and distribute resources appropriately (e.g. in response to gaps or highest need areas).

These applications are extremely valuable to planning; however, the availability of public health information within a robust and functional online environment remains in a nascent state (Croner 2003), thus limiting the utility of DSS (Yigitcanlar 2006). As noted in the review of health system in Queensland, information does exist but is not being used effectively. This paper describes a possible framework for organising information within a DSS. The paper also introduces an online GIS-based DSS for improving local collaborative health planning in practice and outlines the process that is being 
implemented through a partnership consisting of university researchers, a Queensland Health (QH) Service District, local government authorities, and the non-profit sector within the Logan-Beaudesert area.

This study is a response taken by the partnership to address effectively the growing level of chronic disease risk factors in the region. It was initiated with a view to improving health capacity at multiple levels through improved and responsive localised planning. The partnership has been labelled the Logan-Beaudesert Health Coalition (LBHC) and oversees six health initiatives, each focusing on a specific area identified as needing attention. These health initiatives focus on the early years of life (0 to 8 years), multicultural health, prevention and management of existing chronic disease, integration between general practice and acute settings, efficient management and transfer of health information, and health promotion. The initiatives and their advisory groups are responsible for facilitating decisions, polices or strategies by providing recommendations and information to the LBHC board. At the board level, decisions are made and recommendations are reflected back to policy-makers; thus, the DSS is the interface where policy-makers and members of the community 'meet' to engage in collaborative and informed planning.

\section{The healthy communities approach}

In the last few decades, the community health agenda has become more relevant to urban planning and policy-making as a result of trends such as rapid urbanisation, over-development, global warming and the increased incidence of chronic diseases. Towns, cities and communities are committing to the promotion of sustainable development and healthy places, inspired by initiatives such as the World Health Organization (WHO) Healthy Cities movement and the 1986 Ottawa Charter (WHO 1997, 1999; Duhl \& Sanchez 1999; Satterthwaite 1999; Logan City Council 2003; Ashton 2009). Proponents of this approach now face two key challenges: how to shift health promotion from the margins into the mainstream, and how to integrate multiple forms of information and crosssectoral thinking into the planning process. Such a shift will ensure that health planning can contribute to the development of healthy communities through healthy public policy (Dooris 1999).

The promotion of healthy public policy has been noted as being central to the healthy communities approach (Flynn 1996). In order to deliver such policy, health planning must move beyond its current approaches that are dominated by the needs of the acute sector. Rather than being confined to decisions about the response to specific issues based on a narrow body of disease-related knowledge, planning requires a focus on the whole community and the promotion of health at its broadest level. Healthy communities are based on models of city governance in which public authorities recognise the need to work with and support a range of actors who are either fully committed to health or play a significant role in contributing to the conditions that promote health (WHO 1997). Thus, at the very least, planning must become collaborative and draw on a diverse body of information that fully represents the complexity of the community itself and responds to the broad determinants of health. In the optimum situation, planning must lead to public policy within all sectors that is conducive to the promotion of healthy and sustainable places.

A growing number of case studies illustrate innovative and successful approaches to health and environmental problems. For instance, the city of Belo Horizonte, Brazil, developed a 'participative budgeting' approach that allowed citizens a higher level of involvement in priority-setting for municipal investments (WHO 1999). Another example is the city of Cali, Columbia, where municipal programs were designed by complex partnerships (non-government, government and religious organisations) to improve housing, reduce poverty and improve environmental conditions (WHO 1999). Evidence has suggested that, with good health management, health 'competence' and public participation, cities can become healthy places (WHO 1999).

The success of healthy communities projects depends upon their ability to generate innovation that, in turn, depends upon the creation of a climate that supports knowledge and change (WHO 1997); for instance, spreading knowledge about programs and practices is essential. The recent research of Kazada et al. (2009), however, has revealed a number of challenges for collaborative-based health planning, including lack of community readiness and challenges in balancing current action with capacity-building for the future, but most importantly, insufficient attention to processes such as 
technology and 'knowledge transfer'. Being responsive to these challenges may lead to better organisational structure, improved intervention planning, and effective public participatory processes within the community.

The healthy communities movement has heightened the need to restructure the way health decision-making occurs, shifting power to the local level and making decisions based on a localised but broader body of information. Complex planning for healthy communities requires collaboration between different groups in the community that can contribute to health-promoting conditions; these groups include local government, community organisations, universities, private organisations and health services. Policy-makers and stakeholders must be able to formulate more comprehensive policies that are acceptable to the community and provide opportunities for the public to maintain an engagement in their own health. However, in this new context, decision-making processes have become more challenging than ever. Decision-makers must be able to understand a range of complex, unstructured or semi-structured problems that impact on health status (Simon 1960; Gorry \& Morton 1971; Shim et al. 2002). They must be able to monitor the causes of health problems and access the necessary information to support complex decision processes. These are significant challenges.

Due to the lack of information, decisions in the policy domain are often made on the basis of individual experience and judgement. For instance, Duckett (2007) observed that policy makers lament the paucity of nationally comparable data and that there is a lack of systematic information that may lead to a gap in the policy coverage. Thus, although it is essential to respect the judgements and choices of decision-makers, it is equally necessary to ensure that the decision-makers are as well informed as possible. Despite the lack of procedure for conducting collaborative planning in practice, this approach is being increasingly advocated and implemented in the context of healthy communities.

The processes of collaborative planning and informed decision-makers (Murray 2006) provide decision-makers with the ability to:

- $\quad$ combine information, knowledge and skills from multiple stakeholders (Margerum 1999)

- generate agreement over solutions (Innes \& Booher 1999)

- $\quad$ create sense of ownership over the outcomes (Mitchell 1997)

- $\quad$ increase support for implementation (Mitchell \& Hollick 1993)

- $\quad$ open communication channels between participants (Buchy \& Race 2001)

- $\quad$ achieve mutual learning and personal growth from participants (Sager 1994; Healey 1997; Buchy \& Race 2001)

- $\quad$ increase democratisation of the decision-making process (Forester 1989; Sager 1994; Healey 1997). Three main features of collaborative planning

thus make it ideal for application within the healthy communities approach. First, collaborative planning promotes democratic decision-making that facilitates shared ownership and engagement in solutions (Murray 2006). Second, it encourages planners to communicate, interact and negotiate with other sectors in order to resolve disputes between groups that may have some investment in the planning process (Campbell \& Fainstein 1996). Third, it facilitates a more collaborative form of governance that, in turn, implies a more collaborative and efficient delivery of health promotion practices (Bishop \& Davis 2001). Therefore, collaborative planning has potential to become a fundamental approach to planning (Murray 2006). However, this new approach to planning is disadvantaged by the lack of a method for sharing information in a meaningful way. Without such a method, collaborative processes are hindered and the benefits outlined by Murray (2006) may not be realised. Whereas each healthy city project must find its way through the maze of ever-changing local circumstances (WHO 1997), an overarching framework to guide information-seeking efforts and a structured process for sharing that information is essential. In the absence of this type of framework, information is likely to be used uncritically and decisions may become arbitrary.

\section{Decision support systems in the context of collaborative health planning}

DSS are ICT tools that provide the mechanisms to help decision-makers and related stakeholders assess complex problems and solve these in a meaningful way (Shim et al. 2002). The rise of DSS has been facilitated by the increased 
knowledge capacity of organisations, brought about by improvements in data storage and information processing and reduced cost of software, licensing and hardware. Consequently, it is now more possible than ever before to make use of ICT-based DSS in health planning.

DSS incorporates two main domains: 1) policy-making, which entails making decisions to solve problems; and 2) technology, which uses computational problem solving tools. The policy domain requires multi-faceted considerations, such as costs, benefits, time span, contingent effects of actions and stakeholder involvement (Dur et al. 2009). The overall aim of DSS, without substituting decision-makers, is to improve the efficiency of the decisions made by stakeholders, optimising their overall performance and minimising judgemental biases (Turban 1993).

Due to the multi-dimensional geographical information needs of urban and health planners, it is imperative that DSS be based on a spatial component (Keenan 2006). GIS is usually considered as a central spatial component of DSS as it embraces computational, analytical, problem solving and visualisation capabilities (Gudes et al. 2009; Dur, Yigitcanlar and Bunker 2009); for instance, Conway, Rizzuto and Weiss (2008) indicated that spatial maps might be particularly helpful to stakeholders, improving decision-making by visualising and simulating spatial phenomena. The advantage of a GIS-based DSS is that it enables visualisation of input information, decision process, and assessment of analysis and results (Yigitcanlar 2008). This capacity to share information in a variety of forms improves stakeholders' involvement in decision-making, horizontal knowledge sharing and simplicity of the decision process (Dur, Yigitcanlar \& Bunker 2009). GIS provides the computational, analytical, problem-solving and visualisation capabilities necessary for a spatial DSS (Dur, Yigitcanlar \& Bunker 2009). It allows planners to develop powerful and effective spatial techniques to address complex questions about the determinants of health. Spatial analysis, however, needs to be based on solid understanding of these broad influences on health outcomes (Mooney \& Fohtung 2008). According to Mooney and Fohtung (2008), thorough understanding of the complex relationships between social determinants and health may lead to more knowledgeable interpretation of health-related findings. It is therefore imperative that the DSS be based on a broad information framework.

\section{An information management framework for GIS-based DSS}

Despite the value of collaborative health planning, it seems that its ability to contribute to the healthy communities movement has been limited by the absence of clear and practical frameworks and methods that can underpin decision-making. Specifically, frameworks are needed to determine the type of information that must be considered by health planners. Further, methods are necessary to promote the effective sharing of information across multiple decision-makers in multiple contexts. However, the development of this type of framework and method is not a simple matter: as Flynn (1996) has argued, every community is unique, with different physical, social, political and cultural contexts that must be understood in the planning process. It is necessary, then, for planners to develop a thorough understanding of each individual community health profile and the structural features that influence health. For this reason, the framework that is used to structure information must not be overly prescriptive, but should organise information in a way that directs the attention of policy-makers to the entire range of conditions and structures that influence health (Gudes, Yigitcanlar \& Pathak 2009).

In this regard, a potential framework to underpin DSS has been provided by Schulz and Northridge (2004), and is illustrated in Figure 1. Originally developed as a public health framework for health impact assessments, this framework summarises the different levels of factors that impact upon health and, therefore, should be considered in health planning. The framework covers diverse areas (i.e. health, environment, community, non-government, social processes, etc.), thus engaging multiple stakeholders in the process of knowledge sharing. According to Northridge, Sclar and Biswas (2003) the factors that contribute to health can be divided into four levels, namely: macro, meso, micro and individual. These factors interact to contribute to overall health status in the community. For instance, at the macro level the natural environment, social factors, and broad inequalities (i.e. fundamental factors) influence health outcomes and wellbeing (i.e. individual level) via multiple pathways created by differential access to power, information, and resources. The relationships between these fundamental factors and the individual level outcomes are mediated by intermediate factors (i.e. the built environment and the social 
context). This level of the built environment is usually the focus of urban planners and becomes the subject of policy management (Northridge, Sclar \& Biswas 2003). The relationships are also mediated by a range of proximate factors that are more often the realm of public health practitioners. At this level, three domains are considered to be important: stressors, social integration or support, and health behaviours. These proximate factors have been given the greatest scientific attention in recent years (Northridge, Sclar \& Biswas 2003), whereas the broader macro-level determinants of health are often overlooked by planners. Health outcomes and well-being can be considered at either the population level or the level of the individual and sub-groups within the community. In sum, this framework clearly provides a useful organising structure for a DSS to support collaborative planning for a healthy community initiative.

The application of the Northridge, Sclar and Biswas (2003) framework to the management of local information will provide a solid foundation for the DSS and enable a more comprehensive understanding of the local health profile. The framework will thus ensure a meaningful basis on which to make decisions that will contribute to the development of a healthy community.

Enthused by the Schulz and Northridge (2004) framework a team of experts, including the authors of this article, has undertaken a trial of an online GIS-based DSS. The DSS has an easy-to-use online interface and localised functionality, designed in conjunction with our stakeholders. It is designed for the purpose of making information accessible to a wide range of policy-makers, stakeholders and the community in a usable and useful form to facilitate their collaborative decision-making processes.

All sources of information to populate the cells of the Informational Components Framework (Table 1) have been collected at the time of writing. This repository of data resides within a unique online environment that can facilitate its growth and maintenance over time. Through a participatory research method, we are working collaboratively with the local stakeholders to improve the design of the DSS and its functionality, enhance its key domains and the nature of its web-based interface, respond to the local information needs, and explore the types of spatial questions that will be addressed. It is expected that through this iterative process, the engagement and empowerment of the pertinent stakeholders will take place at the same time as continuous improvement of the DSS utility.

Given that the health decision-makers rarely have access to information about the broad social and environmental determinants of health, the comprehensive standpoint of this framework may provide an exceptional foundation for collaborative health planning. Further research will examine the impact of this approach on decision-makers and their policy outputs, based on the assumption that the information from a broader perspective should lead to an effective collaborative health planning practice.

\section{Linking GIS-based DSS with collaborative health planning}

To date, few health planning initiatives have utilised a GIS-based DSS as the basis of collaborative health planning in Australia. Despite the fact that modern DSS technology, including software and fast personal computers, has been available for at least a decade, the incorporation of DSS technologies into public health management and practice in Australia is only in its early days (Queensland Health 2005). Dynamic applications in an online environment are less easily identified in the health literature (Baum et al. 2010).

Some examples and case studies of DSS frameworks used for health planning can be found in Australia (Melbourne City Council 2008). Tools such as health service access maps or limited DSS applications can be found in the following departmental initiatives:

- Victorian Department of Human Services

- South Australian Department of Human Services

- Western Australia State Parental Reference Group

- Commonwealth Department of Health and Aged Care, and 
- $\quad$ Central Northern Adelaide Health Service.

International examples of collaborative online DSS provide some illustrations of its utility (Baum et al. 2010); for example, health service access maps or DSS applications have been used by the Population Health Surveillance Unit of the Vancouver Island Health Authority, Canada and the USA National Cancer Institute.

The majority of DSS applications, however, focus on specific health issues such as the National Diabetes Service Scheme and the Social Health Atlas of Adelaide Health Service website (Central Northern Adelaide Health Service 2008), rather than the promotion of community health through broad place-based planning. These disease-specific applications lack the communication channels and the public participation mechanisms that are imperative for collaborative health planning. An online health DSS therefore should embrace the following features: knowledge sharing, a public participation mechanism, and the facilitation of evidence-based decision-making. This combination may exert a vigorous impact on community health.

Different approaches have been applied in assessing health outcomes and risk factors; for instance, Hancock (1993) presented a conceptual framework for planning healthy cities based on the three main themes of community, environment, and economy. This study has provided a more comprehensive information management framework based on the work of Schulz and Northridge (2004) on health impact assessment. There is, however, a little knowledge about the potential role and implications of GIS-based DDS in collaborative health planning initiatives.

Figure 2 illustrates the overall place of DSS within a healthy communities initiative. Specifically, it is proposed that the Information Management Framework based on Schulz and Northridge (2004) should guide the development of a community health profile, with information being derived from multiple sources. Eagar, Garrett and Lin (2001) emphasised that the demographic, socioeconomic, epidemiological, mortality, morbidity, health services activity, health economic data and clinical evidence may all be relevant informational components for health planning processes. Their ability to present this information in meaningful ways is a critical challenge for establishing healthy communities.

Most of the macro- and meso-level variables of study were derived from Australian Bureau of Statistics (ABS) publications. ABS data were extracted for our area of interest, which was based on 31 Statistical Local Areas (SLAs). The data were tied into new GIS layers based on the proposed framework. Other datasets were retrieved from federal, state and local governments and organisations (e.g. Queensland Police Service, Queensland Health, Medicare Australia, Logan City Council, Scenic Rim Council, Queensland Department of Environment). Other variables were gathered from local sources as needed: for instance, the fast food outlets layer was constructed using the public-domain (e.g. yellow-pages and internet) to identify local fast food providers by their addresses. This process is named ‘Geocoding' in the GIS jargon.

Few issues of data accessibility have been encountered because the bulk of DSS data were based on information retrieved from the public-domain. Most of the data were derived from large organisations that have existing quality assurance processes; however, data quality was an issue of concern. Data derived from local sources were checked carefully and collection processes were reviewed. Feedback will be requested from the DSS end-users throughout its life cycle, in order to monitor data quality.

Importantly, the process of developing the DSS has been based on Participatory Action Research (Minkler 2000). In this method, stakeholders (e.g. health system end-users) have been consulted in iterative cycles, with each consultation feeding into the further refinement and development of the DSS. This first phase of DSS development has focused on the information management framework and the data collection. Future iterations will focus on the development of an interactive interface, preferred features of the DSS, use of the system and perceived reliability of the outputs. The project team will also seek evidence and guidance about weightings for part of the variables to enable predictive spatial modelling. The DSS will be developed within the context of a rigorous health planning model that will facilitate its integration with other sources of knowledge and collaborative decision-making processes.

Data are also being collected to examine the impact of the DSS on the stakeholders in terms of their decision-making processes, satisfaction and effectiveness. The DSS thus becomes the 'place’ where policy-makers and stakeholders 'meet'. It is proposed that this ‘place’ will support collaborative and evidence-based decision-making and contribute to a broader 
conceptualisation of the health-related issues to be addressed in this community.

As a result of this collaborative, knowledge-sharing process, there is a greater likelihood that comprehensive and robust public policy will be developed at all levels of the community. It is also more likely that policy across a range of domains will be responsive to health needs, even if health is not its primary purpose. This type of policy making is likely to contribute to the six conditions thought to characterise healthy commu-nities as described by the World Health Organization (1997): these conditions include health public policy, innovation, community participation, intersectoral action, political decision-making (i.e. oriented towards health topics) and commitment to health. A healthy community may not require the presence of all these indicators, but should exhibit some indicators within each of the six areas that characterise a healthy city (WHO 1997).

\section{Challenges, potential impact and practicalities for Health Information Managers}

As Todd and Southon (2001) noted, developments in the area of knowledge and its representation through ICT applications is likely to present significant opportunities and challenges for all information professionals, whether or not they are central to the knowledge management endeavour. In the health sector, Health Information Managers (HIMs) are generally responsible for the design and management of information systems. They collect and generate data, establish and monitor systems, and play a key role in the security and legal use of health information. Thus, the implementation of GIS-based DSS is likely to have a major impact on HIMs. Similarly, the experience of HIMs about how to implement and manage systems will be crucial to those who wish to apply spatial knowledge to health planning in future.

It is likely that HIMs may need to become skilled and familiarised with GIS methodologies. In particular, they would require awareness of web-based GIS modules and how they can be integrated onto broader health information systems. They will also face increasing demand to develop their understanding of different datasets (i.e., broad determinants of health as opposed to individual clinical administrative data). HIMs may need to reconceptualise their approach to data, adopting a spatial orientation rather than only traditional ways of viewing data.

In terms of what HIMs can bring to the DSS, the opportunities are substantial (i.e. support to implement this complex methodology in the health sector, linkages between data custodians and policy-makers, contribution to the design and maintenance of relevant and meaningful interfaces, management of data privacy and security, knowledge of available datasets). Most importantly, HIMs are likely to play a significant role in the process of ensuring that this new technology is used and applied effectively in future (Kraemer, King \& Maggi 1983).

\section{Conclusion}

This paper has highlighted the necessity for a comprehensive information management framework to underpin collaborative planning for healthy communities. The proposed framework encourages planners to engage with the entire range of health determinants, but also provides sufficient flexibility to allow exploration of the local circumstances. Moreover, the study has adopted the data collection method suggested by Leggat (2009), who emphasised that information should be based on several sources and that multiple data collection approaches have a significant positive influence on the capacity of decision-makers. Furthermore, the paper has discussed the need for an online interactive GIS-based DSS to manage information and facilitate the effective and meaningful dissemination of information across a range of stakeholders in multiple forms. Questions about how the suggested framework and method are actually applied in local communities, the impact of the DSS on decision-making and its ability to facilitate collaborative-based health planning, remain unanswered and form the basis of our ongoing research. The role of HIMs in the development and acceptability of GIS-based DSS is significant.

\section{References}

Ashton, J.R. (2009). From healthy towns 1843 to healthy cities 2008. Public Health 123(1): 11-13. 
Auditor-General of Queensland (2009). Report to Parliament no. 2 for 2009: health service planning for the future - a performance management systems audit. Brisbane, Queensland: Queensland Audit. Available at: http://www.qao.qld.gov.au/downloadables/ publications/auditor_general_reports/2009_Report_No.2.pdf (Accessed 1 August 2008).

Barnard, D.K. and Hu, W. (2005). The population health approach: health GIS as a bridge from theory to practice. International Journal of Health Geographics 4(23) doi:10.1186/1476-072X4-23. Available online from: http://www.ij-healthgeographics. com/content/4/1/23.

Baum, S., Kendall, E., Muenchberger, H. and Gudes, O. (2010). Geographical information systems and on-line decision support platforms: useful tools for community health coalitions in Australia. Unpublished paper.

Blum, H.L. (1974). Planning for health: development and application of social change theory. New York: Human Sciences Press.

Bishop, P. and Davis, G. (2001). Developing consent: consultation, participation and governance. In Are You Being Served? Eds. G. Davis and P. Weller. Sydney, Allen \& Unwin: 175-195.

Buchy, M.N. and Race, D. (2001). The twists and turns of community participation in natural resource management in Australia: what is missing? Journal of Environmental Planning and Management 44(3): 293-308.

Campbell, S. and Fainstein, S.S. (1996). Introduction: the structure and debates of planning theory. In Readings in urban theory, Eds.

S. Campbell and S.S. Fainstein. Oxford, Blackwell Publishing: 1-16.

Central Northern Adelaide Health Service (2008). Central Northern Adelaide Health Service Social Health Atlas 2008. Available at: http://www.publichealth.gov.au/interactive_mapping/sa_sha_cnahs_2005/atlas.html.html (accessed November 24, 2008).

Conway, M.D., Rizzuto, C.D. and Weiss, L.M. (2008). A better way to speed the adoption of vaccines. McKinsey Quarterly. Available at:

http://www.mckinseyquarterly.com/home.aspx (accessed 20 November 2008).

Cromley, E.K. and McLafferty, S.L. (2002). GIS and public health. Health \& Place. 9(3): 279.

Croner, C.M. (2003). Public health, GIS and the internet. Annual Review of Public Health 24: 57-82.

Dooris, M. (1999). Healthy cities and local agenda 21: the UK experience - challenges for the new millennium. Health Promotion International 14(4): 365-375.

Duckett, S.J. (2007). The Australian health care system (Third edition). South Melbourne, Oxford University Press.

Duhl, L. and Sanchez, A. (1999). Healthy cities and the city planning process - a background document on links between health and urban planning. WHO Regional Office for Europe, Copenhagen.

Dur, F., Yigitcanlar, T. and Bunker, J. (2009). A decision support system for sustainable urban development: the integrated land use and transportation indexing model. Proceedings of the Postgraduate Infrastructure Conference. Brisbane, Australia, 26 March. Queensland University of Technology.

Eagar, K., Garrett, P. and Lin, V. (2001). Health planning: Australian perspectives. Sydney, Allen \& Unwin.

Flynn, B.C. (1996). Healthy cities: toward worldwide health promotion. Annual Review of Public Health 17: 299-309.

Forester, J. (1989). Planning in the face of power. Berkeley, University of California Press.

Gorry, G.A. and Morton, M.S.S. (1971). A framework for management information systems. Sloan Management Review 13(1): 55-70.

Gudes, O., Yigitcanlar, T. and Pathak, V. (2009). A community health support system for the planning of healthy cities. Proceedings of the Postgraduate Infrastructure Conference. Brisbane, Australia, 26 March. Queensland University of Technology.

Gudes, O., Yigitcanlar, T., Tal, Y. and Bar-Lavi, Y. (2009). Innovative geography standards for web-GIS portals: case study of the Survey of Israel's Web-GIS Portal. 2009 FIG Working Week: Surveyors Key Role in Accelerated Development, 3-8 May 2009, Eilat, Israel.

Hancock, T. (1993). Health, human development and the community ecosystem: three ecological models. Health Promotion International 8(1): 41-47.

Healey, P. (1993). Planning through debate: the communicative turn in planning theory. In The argumentative turn in policy analysis and planning. Eds. F.

Fischer and J. Forester. Durham and London, Duke University Press: 233-249.

Healey, P. (1997). Collaborative planning: shaping places in fragmented societies. Vancouver, University of British Columbia Press.

Higgs, G. and Gould, M. (2001). Is there a role GIS in the 'new NHS'? Health \& Place 7(3): 247-259.

Innes, J. and Booher, D. (1999). Consensus building and complex adaptive systems. Journal of the American Planning Association 65(4): 412-423.

Kazada, M.J., Beel, E.R., Villegas, D., Matinez, J.G., Patel, N. and Migala, W. (2009). Methodological complexities and the use of GIS in conducting a community needs assessment of a large US municipality. Journal of Community Health 34(3): 210-215.

Keenan, P.B. (2006). Spatial decision support systems: a coming of age. Control and Cybernetics 35(1): 9-27.

Kraemer, K.L., King, J.L., and Maggi, L. (1983). Effectively utilising computer-aided design technology: the role of individual difference variables. Proceedings of the Fifth International Conference on Information Systems. Tucson, Arizona, United States, 28-30 November. Association for Computing Machinery.

Leggat, S.G. (2009). Hospital planning: the risks of basing the future on past data. Health Information Management Journal 37(3): 6-14.

Logan City Council (2003). Logan Public Health Plan 2003-2008. Logan, Logan City Council.

Margerum, R. (1999). Integrated environmental management: the foundations for successful practice. Environmental Management 24(2): 151-166.

Melbourne City Council (2008). Melbourne 2030 planning for sustainable growth. Melbourne: Melbourne City Council. Available at: www.melbourne2030.vic.gov.au (accessed 15 November 2008).

Minkler, M (2000). Using participatory action research to build healthy communities. Public Health Reports 115(2-3): 191-197.

Mitchell, B. (1997). Resource and environmental management. Oxford, Oxford University Press.

Mitchell, B. and Hollick, M. (1993). Integrated catchment management in Western Australia: transition from concept to implementation. Environmental 
Management 17(6): 735-743.

Mooney, G. and Fohtung, N.G. (2008). Issues in the measurement of social determinants of health. Health Information Management Journal 37(3): 26-30.

Murray, D.J. (2006). A critical analysis of communicative planning theory as a theoretical underpinning for integrated resource and environmental management. Unpublished PhD thesis, Griffith University, Queensland.

National Health and Hospitals Reform Commission (2009). A healthier future for all Australians. Final report. June. Canberra, ACT, National Health and Hospitals Reform Commission.

Northridge, M.E., Sclar, E.D. and Biswas, P. (2003). Sorting out the connections between the built environment and health: a conceptual framework for navigating pathways and planning healthy cities. Journal of Urban Health 80(4): 556-568.

Plescia, M., Joyner, D.R. and Scheid, T.L. (2004). A regional health care system partnership with local communities to impact chronic disease. Preventing Chronic Disease 1(4): 1-8.

Queensland Health (2005). Report on GIS and public health spatial applications. Brisbane, Public Health Services.

Reeves, P.N. and Coile, R.C (1989). Introduction to health planning. Arlington, VA: Information Resources Press.

Reinke, W.A. (1972). Health planning: qualitative aspects and quantitative techniques. Baltimore, MD: Johns Hopkins University School of Hygiene and Public Health, Department of Internet Health.

Sager, T. (1994). Communicative planning theory. Brookfield, Avebury Press.

Satterthwaite, D. (1999). The Earthscan reader in sustainable cities. London, Earthscan.

Schulz, A. and Northridge, M.E. (2004). Social determinants of health: implications for environmental health promotion. Health Education \& Behaviour 31(4): 455-471.

Shim, J.P., Warkentin, M., Courtney, J.F., Power, D.J., Sharda, R. and Carlsson, C. (2002). Past, present, and future of decision support technology.

Decision Support Systems 33(2): 111-126.

Simon, H. (1960). New science of management decision. New York, Harper and Row.

Todd, R.J. and Southon, G. (2001). Educating for a knowledge management future: perceptions of library and information professionals. The Australian

Library Journal 50(4): 313-326.

Turban, E. (1993). Decision support and expert systems: management support systems. Upper Saddle River, NJ, Prentice Hall.

World Health Organization (1997). Twenty steps for developing a healthy cities project. WHO Regional Office of Europe.

World Health Organization (1999). Health: creating healthy cities in the 21st century. In The Earthscan reader in sustainable cities. Ed. D, Satterthwaite.

London, Earthscan: 137-172.

Yigitcanlar, T. (2008). Public oriented interactive environmental decision support system. In GIS and evidence-based policy making. Eds. S. Wise and M.

Craglia, A. Anttiroiko. London, Taylor and Francis: 347-366.

Yigitcanlar, T. and Gudes, O. (2008). Web-based public participatory GIS. In Encyclopedia of decision making and decision support technologies. F. Adam

(Ed.). Hersey, PA, Information Science Reference, Volume II: 969-976.

Yigitcanlar, T. (2006). Australian local governments practice and prospects with online planning. URISA Journal 18(2): 7-17. 
Corresponding author: Ori Gudes MA PhD Candidate, Queensland University of Technology Faculty of Built Environment and Engineering School of Urban Development Research Fellow, Griffith Institute of Health and Medical Research Griffith University Logan Campus Meadowbrook QLD 4131 AUSTRALIA email: ori.gudes@student.qut.edu.au or o.gudes@griffith.edu.au

Elizabeth Kendall PhD Professor Griffith Institute of Health and Medical Research (and Centre of National Research on Disability and Rehabilitation Medicine) Griffith University Logan Campus Meadowbrook QLD 4131 AUSTRALIA email: e.kendall@griffith.edu.au

Tan Yigitcanlar PhD Senior Lecturer Queensland University of Technology Faculty of Built Environment and Engineering School of Urban Development 2 George St, Brisbane QLD 4000 AUSTRALIA email: tan.yigitcanlar@qut.edu.au

Virendra Pathak PhD Lecturer Queensland University of Technology Faculty of Built Environment and Engineering School of Urban Development 2 George St, Brisbane QLD 4000 AUSTRALIA email: virendra.pathak@qut.edu.au

Scott Baum PhD Professor Urban Research Program Griffith University Nathan Campus Nathan QLD 4111 AUSTRALIA email:s.baum@griffith.edu.au 


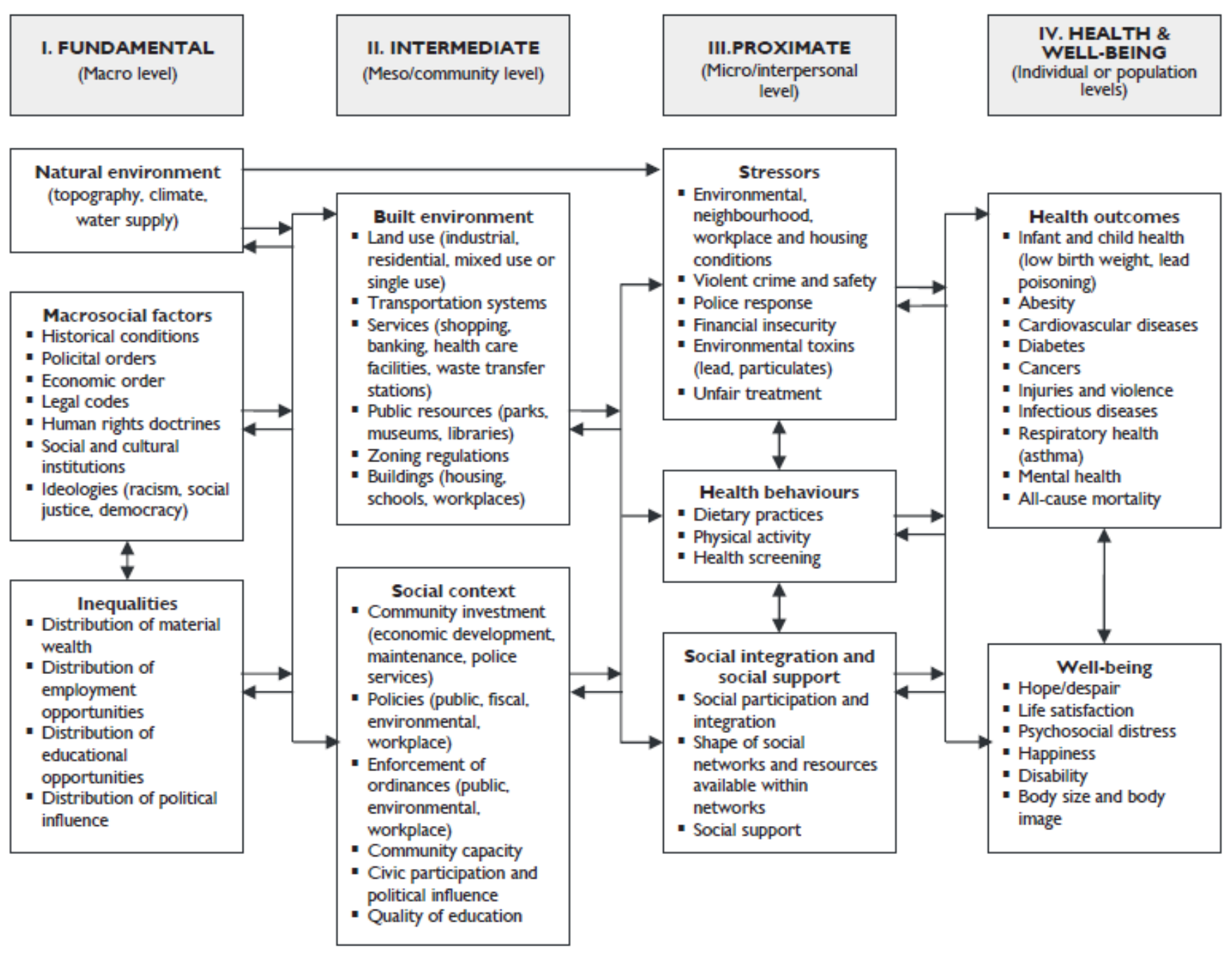

Figure 1: Public health framework for use in health impact assessment and health profiling (Schulz \& Northridge 2004) 


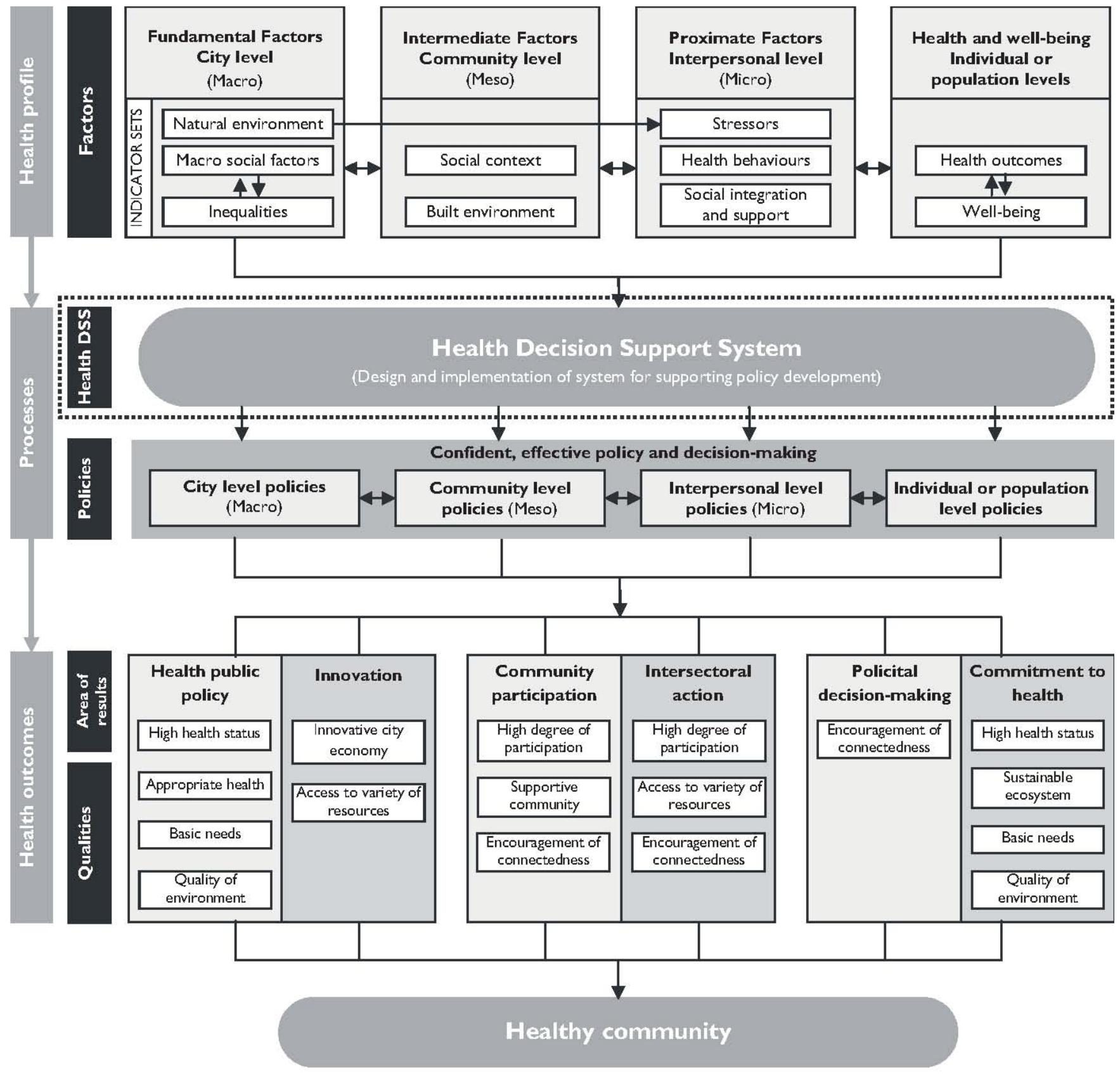

Figure 2: A conceptual framework for the planning of a healthy community (derived from World Health Organization 1997: Schulz \& Northridge 2004) 